\title{
Representaciones narrativas de la mujer en el cine de ficción costarricense (2008-2012)
}

\section{José Andrés Fonseca Hidalgo'}

\author{
Resumen Recepción: 16 de enero de 2017 / Aprobación: 26 de mayo de 2017
}

El presente artículo busca conocer cuáles son las representaciones narrativas dominantes de la mujer en los largometrajes de ficción costarricenses estrenados entre los años 2008 y 2012. Para ello, 15 textos fílmicos se analizan desde tres perspectivas distintas: la cuantificación simple de protagonistas mujeres; la identificación de funciones actanciales recurrentes para los personajes femeninos dentro de las historias y, por último, la aplicación del “Test de Bechdel”. El estudio evidencia una marcada desigualdad en la cantidad de obras realizadas por mujeres frente a aquellas realizadas por hombres; construcciones distorsionadas de lo femenino y el predominio de una mirada masculina que articula la representación de la mujer como subordinada al hombre. Estas características reafirman las preocupaciones centrales de la Teoría Fílmica Feminista y nos llevan a plantearnos soluciones para minimizar la violencia simbólica en el contexto de una industria cinematográfica en auge.

\section{Palabras clave}

Teoría fílmica feminista; semiótica fílmica; narratología; cine de ficción; Test de Bechdel

\section{Abstract}

This article sets out to identify the dominant narrative representations of women in costarrican feature films between the years 2008 and 2012. It analyzes 15 film texts from three separate perspectives: the simple tally of women protagonists; the recurring actantial functions of female characters within the stories; and the outcome of the "Bechdel Test". The study shows the inequality in authorship between men and women; distorted constructions of femininity; and the prevalence of a "male gaze" which shapes the representation of women as subordinated to men. These traits reassert the main concerns of Feminist Film Theory, and urge us to search for ways in which to minimize symbolic violence in the context of a thriving film industry.

1 Costarricense. Doctor en Estudios de Cine, Máster en Escritura de Guión por la Universidad de Bergen (Noruega). Licenciado en Producción Audovisual, Bachiller en Ciencias de la Comunicación Colectiva por la Universidad de Costa Rica (UCR). Docente e investigador de la Escuela de Ciencias de la Comunicación Colectiva (UCR). Correo electrónico: jose.fonsecahidalgo@ucr.ac.cr 


\section{Keywords}

Feminist Film Theory; film Semiotics; narratology; Fiction Film; Bechdel Test

\section{Resumo}

Este artigo explora as representações narrativas dominantes de mulheres em longas-metragens de ficção da Costa Rica, lançados entre 2008 e 2012. Para fazer isso, 15 textos de cinema são analisados a partir de três perspectivas diferentes: a quantificação simples de mulheres protagonistas; a identificação de funções actanciais comuns para personagens femininos nos roteiros; e a implementação do "Test Bechdel". O estudo evidencia: uma acentuada desigualdade no número de obras realizadas por mulheres em relação àquelas feitas por homens, construções distorcidas do feminino e o predomínio de um olhar masculino que articula a representação da mulher como subordinada ao homem. Esses recursos reafirmam as preocupações centrais da Teoria Fílmica Feminista e levam-nos a considerar soluções para minimizar a violência simbólica no contexto de uma indústria cinematográfica florescente.

\section{Palavras chave}

Teoria fílmica feminista; semiótica do cinema; narratologia; Filmes de Ficção; Teste Bechdel

\section{Introducción}

El cine de ficción en Costa Rica es un fenómeno cultural relativamente reciente y, desde el punto de vista histórico, escaso y esporádico. Desde sus inicios en 1930 ("El Regreso" de Albert Bertoni) hasta 1987 ("Eulalia” de Óscar Castillo), solo nueve largometrajes llegaron a realizarse y exhibirse. Luego de eso, tuvieron que pasar 14 años para que el mismo Óscar Castillo reactivara la producción nacional en el 2001 con "Asesinato en el Meneo". Desde ese momento, el cine de ficción costarricense se encuentra en lo que podemos llamar una "era dorada" en cuanto al aumento en la cantidad y frecuencia de las obras de largo formato, con 35 películas estrenadas en los últimos 15 años.

Este "resurgimiento" del cine de ficción también ha posibilitado, tras 73 años de historia, ver a una mujer en un cargo de dirección por primera vez ("Mujeres Apasionadas" de Maureen Jiménez en el 2003), y contar con propuestas generadas desde la perspectiva femenina de autoras como Ishtar Yasin, Hilda Hidalgo, Paz Fábrega, Isabel Martínez, Laura Astorga, Patricia Velázquez y Soley Bernal (ver Figura 1).

Pero, ¿qué hay de la representación de la mujer en las narrativas de nuestro cine de ficción de los últimos años? ¿Cómo ha influido el aumento de proyectos y la presencia y mirada de diversas autoras en la creación de personajes femeninos y sus funciones dentro de estos relatos cinematográficos? 
Partiendo de uno de los postulados centrales de la teoría fílmica feminista -el cual toma el concepto de género como una construcción social moldeada por contingencias culturales e históricas, variable y por tanto reconstruible (Stam, 2000)- cabe preguntarse de qué maneras está aportando el cine de ficción contemporáneo a ese proyecto de percepción sociocultural. Para ello, el presente estudio enfoca su atención en los largometrajes de ficción nacionales exhibidos comercialmente en el país entre los años 2008 y 2012, analizando las funciones retórico-narrativas de sus principales personajes femeninos.

Figura 1. Listado histórico de largometrajes costarricenses de ficción exhibidos comercialmente, 1930-2015 (Mujeres directoras resaltadas en amarillo)

\begin{tabular}{|c|c|c|}
\hline No. & Título y año de estreno & Director(a) \\
\hline 1. & “El Retorno” (1930) & Albert Francis Bertoni \\
\hline 2. & "Elvira" (1955) & Alfonso Patiño Gómez \\
\hline 3. & "Milagro de Amor" (1955) & José Gamboa \\
\hline 4. & "La Apuesta” (1968) & Miguel Salguero \\
\hline 5. & “La Senda Ignorada” (1983) & Ingo Niehaus \\
\hline 6. & “La Segua” (1984) & Antonio Yglesias \\
\hline 7. & “La Negrita” (1985) & Richard Yñiguez \\
\hline 8. & "Los secretos de Isolina” (1986) & Miguel Salguero \\
\hline 9. & “Eulalia” (1987) & Óscar Castillo \\
\hline 10. & “Asesinato en el Meneo” (2001) & Óscar Castillo \\
\hline 11. & "Password: una mirada en la oscuridad" (2002) & Andrés Heidenreich \\
\hline 12. & “Mujeres Apasionadas” (2003) & Maureen Jiménez \\
\hline 13. & “Marasmo" (2003) & Mauricio Mendiola \\
\hline 14. & “Caribe” (2004) & Esteban Ramírez \\
\hline 15. & “El Cielo Rojo” (2008) & Miguel Gómez \\
\hline 16. & “El Camino” (2008) & Ishtar Yasin \\
\hline 17. & “El Psicópata” (2008) & Luis Mena \\
\hline 18. & “La Región Perdida” (2009) & Andrés Heidenreich \\
\hline 19. & “Gestación” (2009) & Esteban Ramírez \\
\hline 20. & “Tercer Mundo” (2009) & César Caro \\
\hline
\end{tabular}

21. "Del amor y otros demonios" (2010)

Hilda Hidalgo

22. "Donde duerme el horror" (2010) 
$23 . \quad$ "A ojos cerrados" (2010)

Hernán Jiménez

24. "El último comandante" (2010)

25.

26.

27.

28.

29.

30.

31.

32.

33.

34.

35.

26.

37.

38. "Maikol Yordan: de viaje perdido" (2014)

39.

40.

41.

42.

43.

44.

\section{"Agua fría de mar" (2010)}

"El Sanatorio" (2010)

"El Regreso" (2011)

"El Compromiso" (2011)

"El Fin" (2012)

"Tres Marías" (2012)

"Princesas Rojas" (2013)

"Puerto Padre" (2013)

"Por las plumas" (2013)

"Padre" (2014)

"Italia 90" (2014)

"Muñecas Rusas" (2014)

"Rosado Furia" (2014)

$$
\text { "Espejismo" (2014) }
$$

"Nina y Laura" (2015)

45. "El lugar más feliz del mundo" (2015)
Isabel Martínez y Vicente Ferraz

Paz Fábrega

Miguel Gómez

Hernán Jiménez

Óscar Castillo

Miguel Gómez

Francisco González

Laura Astorga

Gustavo Fallas

Ernesto Villalobos

Alejo Crisóstomo

Miguel Gómez

Jurguen Ureña

Nicolás Pacheco

Miguel Gómez

José Miguel González

Alejo Crisóstomo

Paz Fábrega

Patricia Velásquez

Esteban Ramírez

Miguel Gómez

\section{Soley Bernal}

Fuente: elaboración propia a partir de Cortés, 2016.

\section{Teoría fílmica y Feminismo: una breve reseña}

Esta propuesta se inscribe en la tradición de la "teoría fílmica feminista", la aplicación a los estudios del cine de la lógica central del feminismo: "explorar las configuraciones de poder y los mecanismos psico-sociales que articulan la sociedad patriarcal, con el fin último de transformar no solo la teoría y crítica del cine, sino también las relaciones de género socialmente jerarquizadas" (Stam, 2000, p. 170, traducción propia). Además de denunciar y concientizar sobre las imágenes negativas de la mujer en los medios, la teoría fílmica feminista también enfoca su atención en analizar cómo la naturaleza misma de la 
mirada cinematográfica reproduce, mediante sus operaciones iconográficas y narrativas, una visión masculinista y subordinada de la mujer (pp. 172-173).

Como lo relata Anneke Smelik (2016), uno de los principales puntos de partida de esta tradición es el trabajo de Claire Johnston en la década de los 70, quien ofrece una crítica semiótica sobre cómo el cine clásico construye una imagen ideológica de la mujer. Explica Johnston que el signo "mujer" representa el significado ideológico que este tiene para el hombre, una imagen esencialmente negativa de la mujer como oposición y carencia: la mujer como "no-hombre". Para Johnston, la "mujer-como-mujer" está, de manera tradicional, ausente de los textos fílmicos, por lo que carece de significado en relación consigo misma. Anota Smelik que la importancia de este aporte teórico consiste en pasar de una visión del cine como "reflejo de la realidad", a una comprensión del mismo como constructor de una visión particular e ideológica de la realidad. La característica invisibilización del aparato productivo del cine tradicional encubre también su construcción ideológica, por lo que la narrativa ilusionista del cine clásico presenta una imagen artificial de la mujer como algo natural, realista y atractivo (p. 491).

No obstante, quizás uno de los textos más influyentes de la teoría fílmica feminista es el artículo de Laura Mulvey, "Visual Pleasure and Narrative Cinema" (1975). En esta obra, la autora utiliza la teoría del psicoanálisis para tratar de comprender nuestra fascinación con el cine narrativo comercial popularizado por Hollywood. Este deslumbramiento, explica Mulvey, proviene del instinto escopofílico: el deseo de ver y la derivación de placer al ver al otro como objeto erótico.

Según la autora (pp. 6-18), el cine tradicional construye la escopofilia desde una estructura de oposición binaria (actividad versus pasividad) que, a su vez, está directamente relacionada con la división de género: la figura femenina es predominantemente pasiva y desempoderada; el objeto de deseo del hombre. El personaje masculino, por otra parte, es activo y poderoso; el agente alrededor del cual se desarrolla la acción dramática y se organiza la mirada cinematográfica. Como lo resume Smelik:

dentro de la narrativa de un film, los personajes masculinos dirigen su mirada hacia los personajes femeninos. La audiencia es llevada a identificarse con la mirada masculina, ya que la cámara filma desde el punto de vista no solo óptico, sino también libidinal, del personaje masculino. Así pues, hay tres niveles de la mirada cinematográfica (la de la cámara, la del personaje, y la del espectador), y en las tres se objetiviza a la figura femenina y se le convierte en espectáculo (2016, p. 491, traducción propia).

Esta "mirada masculina" (male gaze), de la que habla Mulvey, es una maquinaria visual y narrativa que el cine tradicional ha perfeccionado para satisfacer el instinto escopofílico a través de mecanismos de voyerismo, fetichismo y narcisismo esencialmente ligados a la figura del hombre. El placer visual voyerista se produce al ver al otro (sea un personaje, figura, 
o situación) como nuestro objeto. Para Mulvey, la ambigüedad fundamental de la imagen de la mujer (que en el hombre combina atracción y seducción con temor castrante, producto de su diferencia), se resuelve de dos maneras: la ansiedad que implica la ausencia de un pene se compensa narrativamente al establecer la naturaleza "culpable" de la mujer y resolviéndola ya sea mediante a) el castigo o b) la salvación, a manos del hombre; mientras que visualmente, la situación de ansiedad se cancela, convirtiendo a la mujer en un fetiche, un objeto altamente pulido que distrae la atención de su "carencia" y la transforma de una figura peligrosa a un objeto tranquilizador de belleza perfecta (Mulvey, 1975, pp. 17-18).

Por su parte, el placer visual narcisista se deriva de nuestra identificación con las figuras en la imagen. Mulvey destaca este proceso como análogo al de la formación del ego descrito por Jacques Lacan, cuando un niño descubre su imagen en un espejo por primera vez. En un momento en que la ambición física del niño excede su capacidad motriz, su reconocimiento en el espejo es una experiencia gozosa en cuanto percibe su imagen de forma más completa y perfecta de lo que logra experimentar su propio cuerpo. Así, el reconocimiento propio se mezcla con un reconocimiento erróneo (misrecognition) de uno mismo como algo superior que, a su vez alimenta, la formación de un "ego ideal" y nuestra futura identificación con otros (1975, p. 8). De una forma similar, el cine presenta a su audiencia una figura familiar en el héroe masculino, pero, al mismo tiempo, más completa y poderosa, en contraste a la imagen del personaje femenino pasivo y sin poder. Es así que la audiencia deriva placer narcisista al identificarse con esa figura masculina ideal, sobre la igualmente distorsionada figura de la mujer.

La posición de Mulvey fue criticada luego pues, al enfocarse en la "mirada masculina", omite la figura de la mujer como espectadora y la posibilidad de una "mirada femenina". Otras críticas -y la misma Mulvey, en trabajos posteriores- reivindican dicha posibilidad, proponiendo que la mujer espectadora puede no solo identificarse con los roles de feminidad pasiva asignados para ella por el cine dominante, sino también disfrutar de la adopción de un punto de vista masculino (Janet Bergstrom y Mary Ann Doane, 1989); posicionar a los personajes masculinos como objetos de su propio deseo erótico (Miriam Hansen, 1986), o bien, encontrar ese placer en la belleza de la imagen de la mujer representada en la pantalla (Gertrud Koch, 1980).

Gaylin Studlar (1988) y Carol Clover (1992) también ahondan en este último concepto de identificación bisexual. Para Studlar, el placer visual en el cine deriva no del dominio, sino de la sumisión del espectador y espectadora, en este caso, a la figura y la mirada de una figura femenina poderosa. Similarmente, Clover propone que tanto el hombre como la mujer espectador(a) se identifican de forma bisexual, y lo argumenta con el ejemplo del sub-género "slasher" del cine de terror y su convención de la "chica final": el personaje femenino que lucha, resiste y sobrevive al asesino-monstruo. En ese proceso, 
la "chica final" adquiere la mirada, domina la acción y así es masculinizada. Mediante su auto-rescate, se convierte en "el héroe" y, es en ese momento que el hombre espectador abandona sus últimas pretensiones de identificación masculina (Clover citada por Smelik, 2016, p. 495).

Cierra este apartado el estudio que realiza Teresa de Lauretis (1984, 1987) sobre la representación de la mujer en el cine desde la subjetividad y las estructuras narrativas. Explica de Lauretis que nuestra subjetividad no está fijada, sino que se encuentra en un constante proceso de autoproducción. La narrativa es una de las principales formas en que se reproduce esa subjetividad, reafirmando el control sociopolítico del hombre sobre la mujer y enfatizando el origen sexual de la subjetividad misma. Al distribuir roles y establecer diferencias, la estructura narrativa está ejecutando un acto de poder y asignando puntos de vista a los espectadores sobre sí mismos y el mundo. Una de estas funciones, señala la autora, es la de "seducir" a la mujer para que desee conformarse a los estándares de feminidad que se le imponen desde lo narrativo y que responden a la imagen ideal que el hombre tiene de ellas.

Asimismo, de Lauretis explora el tema de la identificación. "Masculinidad" y "feminidad" son identificaciones que el sujeto adopta en una cambiante relación con el deseo. En ese sentido, de Lauretis distingue dos procesos diferentes: la primera es una identificación variable y mutuamente excluyente ya sea con la mirada activa (masculina), o con la imagen pasiva (femenina). La segunda es una identificación doble y simultánea con esos mismos valores. Así pues, este juego de identificaciones permite a la mujer espectadora ocupar posiciones tanto activas como pasivas de deseo ("deseo por el otro, y deseo de ser deseada por el otro") y con ello ampliar sus posibilidades de derivar placer de la experiencia cinematográfica y narrativa. Sin embargo, como lo advierte la autora, esta es la misma operación mediante la cual la narración solicita el beneplácito del espectador(a) y seduce a la mujer hacia la feminidad (de Lauretis citada por Smelik, 2016, p. 496).

\section{De lo semiótico a lo anecdótico: referentes metodológicos}

Además de la teoría fílmica feminista como marco teórico principal, el presente estudio halla sustento metodológico en el campo de la semiótica fílmica (Metz, Eco, Bakhtin), en cuanto analiza la utilización de los signos propios del lenguaje cinematográfico en la generación icónica y culturalmente motivada de sentido (Stam, Burgoyne, Flitterman-Lewis, 1992).

Para este estudio, se utiliza como herramienta principal de análisis el modelo actancial de A. J. Greimas (1966), el cual permite deconstruir y comprender una acción o situación narrativa a partir de seis funciones básicas llamadas "actantes", y sus ejes de relación (ver Figura 2). 
Figura 2. Modelo Actancial de A. J. Greimas

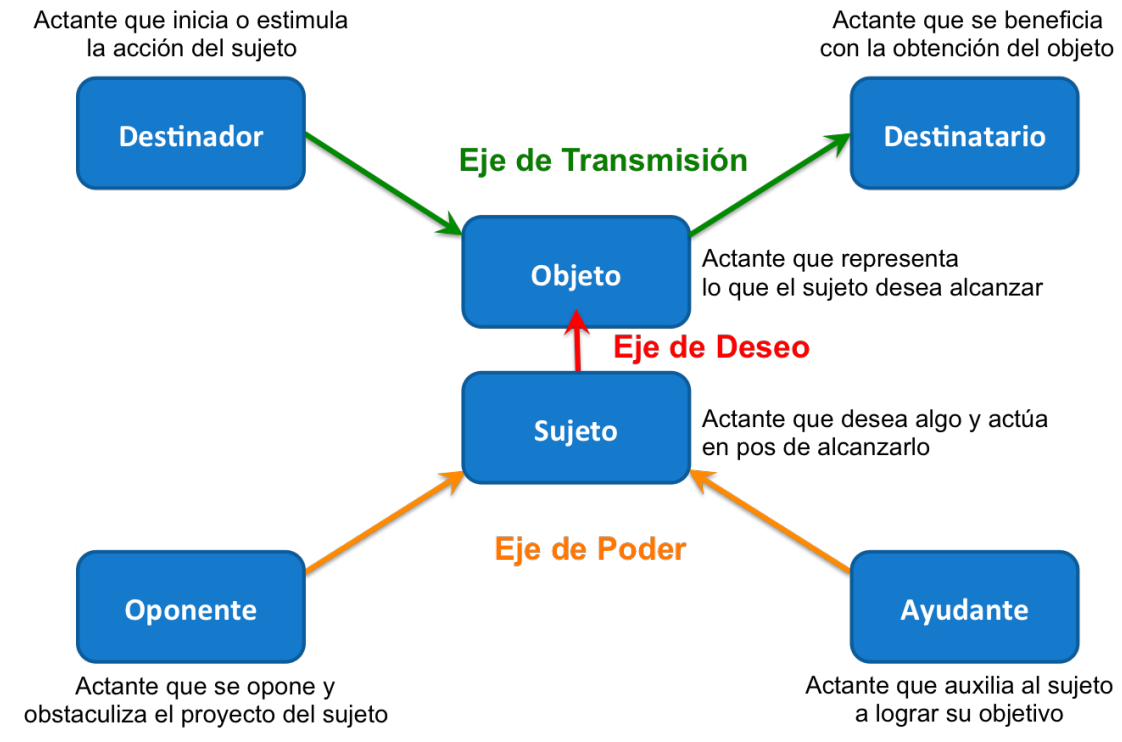

Fuente: Elaboración propia.

Como lo explica Hébert (2006), el núcleo del modelo es el eje del deseo, que se establece entre un sujeto activo que persigue un objeto predominantemente pasivo. Este objeto se presenta como el objetivo o meta del sujeto y el recipiente directo de su accionar. Esta acción del sujeto es a su vez influenciada por fuerzas que lo auxilian (ayudante), u obstaculizan (oponente) en la búsqueda de satisfacer su deseo, y que conforman el eje del poder. Completa el esquema el eje de transmisión. Aquí encontramos a la figura del destinador, que es el actante que estimula el "querer/tener que hacer" del sujeto, y al destinatario, que designa al elemento que se beneficia con la obtención del objeto.

Para Larsen (2002) el modelo actancial es una herramienta analítica sencilla y efectiva, cuya fortaleza radica en su flexibilidad. Esta herramienta tiene la capacidad de dar cuenta de cualquier acción o personaje desde el mismo punto de vista: su posición en relación con el "proyecto central" de la narrativa; pero, al mismo tiempo, nos recuerda el autor que no existe una relación de uno-a-uno entre "personajes" y "actantes": una posición de actante puede ser llenada por diferentes personajes, como también un mismo personaje puede cumplir distintas funciones $-\mathrm{y}$, por lo tanto, representar diversos actantes- a lo largo de un relato (p. 127).

Hébert agrega a este punto diciendo que, si bien cualquier acción real o ficticia puede ser descrita por al menos un modelo actancial, no existe un único modelo actancial para un texto dado. Por un lado, se generan tantos modelos como existan acciones; por otro lado, la misma acción puede ser vista desde distintas perspectivas. Así, por ejemplo, una misma acción podría 
analizarse desde el punto de vista del protagonista-como-sujeto, o de su rival-antagónico-como sujeto (p. 50). El reto, entonces, consiste en definir cómo se aplicará la herramienta al texto de estudio. Hébert describe el proceso de la siguiente forma:

(1) Seleccionar la acción general. (2) Convertir la acción en un modelo actancial primeramente seleccionando el sujeto y el objeto (ya que el resto de actantes son definidos en relación a ese eje) (3) Seleccionar los otros actantes. Estas selección debe estar justificada (¿Dónde se encuentra el elemento dentro del texto? ¿Por qué se considera que es un sujeto, un ayudante, etc.?). Es un error común perder de vista el eje central sujeto-objeto identificado previamente por el analista, y designar destinadores, destinatarios, ayudantes y oponentes que pertenecen a otra relación sujeto-objeto diferente. Por ejemplo, El ayudante no está aliado al sujeto, sino a la relación sujeto-objeto. Si el mejor amigo de un personaje lo ayuda en toda acción excepto la que se establece como el eje central del modelo, entonces ese amigo no es un ayudante en ese modelo particular (Hébert, 2006, p. 50).

Esta investigación busca dar a conocer cuáles son las funciones actanciales predominantes para los personajes femeninos en una muestra de cine de ficción costarricense de los últimos años (ver Figura 3). Para ello, se procede a aplicar el modelo de Greimas de dos formas simultáneas: por un lado, se utiliza la técnica descrita previamente por Hébert, identificando primero al sujeto de acción o "protagonista" de la narrativa, y si este es hombre o mujer. A partir de ello, se determinan los demás actantes para descubrir en cuál de dichas funciones se desempeñan los personajes femeninos del relato en relación a ese eje principal del deseo.

Asimismo -y aprovechando la flexibilidad de la herramienta- cada personaje femenino principal es analizado de manera individual, con el fin de identificar si puede ser considerada dentro de otra función actancial por sus características propias e independiente de su relación al sujeto principal del relato. Esto evita limitar la interpretación de los personajes femeninos únicamente en función de ese otro personaje y su objetivo, observando si exhiben otras funciones actanciales relevantes a la historia, como también sus relaciones particulares con los otros personajes de la narrativa. Así, por ejemplo, un personaje puede cumplir una función de ayudante dentro del modelo principal que coloca al protagonista como el sujeto; pero, al mismo tiempo, ese personaje podría ser sujeto de acción por virtud propia. Al final, lo que se cuantifica es la frecuencia de las distintas funciones actanciales a través de la muestra, con el fin de visualizar los roles dominantes a nivel retórico-narrativo de sus personajes femeninos. 
Figura 3. Muestra de estudio. Largometrajes costarricenses de ficción, 2008-2012 (Mujeres directoras resaltadas en amarillo)

\begin{tabular}{|c|c|c|}
\hline No. & Título y año de estreno & Director(a) \\
\hline 1. & “El Camino” (2008) & Ishtar Yasin \\
\hline 2. & “El Psicópata” (2008) & Luis Mena \\
\hline 3. & “La Región Perdida” (2009) & Andrés Heidenreich \\
\hline 4. & “Gestación” (2009) & Esteban Ramírez \\
\hline 5. & “Tercer Mundo” (2009) & Cesar Caro \\
\hline 6 & "Del amor y otros demonios" (2010) & Hilda Hidalgo \\
\hline 7. & "Donde duerme el horror" (2010) & Adrián y Ramiro García \\
\hline 8. & "A ojos cerrados" (2010) & Hernán Jiménez \\
\hline 9. & “El ultimo comandante" (2010) & Isabel Martínez y Vicente Ferraz \\
\hline 10. & “Agua fría de mar” (2010) & Paz Fábrega \\
\hline 11. & “El Sanatorio” (2010) & Miguel Gómez \\
\hline 12. & “El Regreso” (2011) & Hernán Jiménez \\
\hline 13. & "El Compromiso" (2011) & Óscar Castillo \\
\hline 15. & “El Fin” (2012) & Miguel Gómez \\
\hline 16 & “Tres Marías” (2012) & Francisco González \\
\hline
\end{tabular}

Fuente: Elaboración propia a partir de Cortés, 2016.

Esta información se complementa con una técnica más informal pero igualmente reveladora para extraer algunas conclusiones sobre la representación de la mujer en nuestro cine de ficción. Se trata del llamado "Test de Bechdel", una herramienta de análisis propuesta por la historietista Allison Bechdel en su tira cómica Dykes to Watch Out For ${ }^{2}$. En esta prueba, los casos de estudio se someten a tres simples preguntas para determinar la "presencia activa de personajes femeninos (...) y cuán redondeados y completos son sus roles" (Sarkeesian, 2009). Las condiciones para aprobar el Test de Bechdel son las siguientes: (1) en la película aparecen al menos dos personajes femeninos con nombres; (2) estos personajes sostienen una conversación, y (3) dicha conversación gira en torno a un tema distinto a un hombre.

Según la crítica feminista de medios, Anita Sarkeesian, la cantidad de películas que no pasan esta prueba resulta asombrosa y demuestra como 
las vidas complejas e interesantes de las mujeres son subrepresentadas o invisibilizadas por la industria fílmica. Para Sarkeesian, se trata de un problema sistémico:

No es que hay unas pocas personas aquí y allá que no quieran a las mujeres, o que no deseen que se cuenten historias de mujeres, sino que la industria como un toda está basada en crear películas que apelen a y sean sobre hombres" (Sarkeesian, 2009 en Feminist Frequency, traducción propia).

\section{La representación en cifras: resultados de análisis}

Antes de ahondar en la representación de la mujer en los textos cinematográficos de ficción, es necesario contemplar un aspecto más fundamental: su presencia como enunciadoras de esos discursos fílmicos. Si bien se entiende que el cine es un proceso de creación colectiva donde la noción de autoría individual es debatible, este estudio contempla al director o directora como una figura de importancia central en la formulación y desarrollo de los proyectos.

En contextos de producción mucho más industriales y comerciales, es común que un concepto narrativo sea elaborado primero por un guionista (a menudo, a partir de solicitudes concretas por parte de una empresa productora o "estudio"), y que lleve un considerable proceso de desarrollo previo antes de que la persona elegida para dirigir ingrese al proyecto para una labor más enfocada en coordinar su ejecución audiovisual y actoral. Por otro lado, en cines en formación como el nuestro, la figura del director o directora cumple un papel mucho más cercano e intensivo, siendo gran parte de las veces quien también genera, gestiona y desarrolla la propuesta. Esto hace que la presencia de mujeres en cargos de dirección sea particularmente relevante, por lo que evidencia sobre el grado de acceso de esta población al medio cinematográfico y por la estrecha relación que supone con la obra desde el punto de vista de la autoría discursiva. Dicho de otro modo, las películas hechas por mujeres son de interés no solo por una cuestión de equidad profesional y artística, sino también porque son instancias de expresión que comparten temáticas, perspectivas y posiciones ideológicas íntimamente ligadas a las autoras y a su condición dentro de la sociedad.

No obstante, un vistazo al listado histórico de largometrajes nacionales (Figura 1), demuestra que la autoría femenina es una minoría en nuestra producción cinematográfica de ficción, conformando apenas un 20\% del total de los proyectos realizados desde 1930, contra un $80 \%$ de directores hombres (ver Figura 4). 
Figura 4. Dirección de largometrajes de ficción

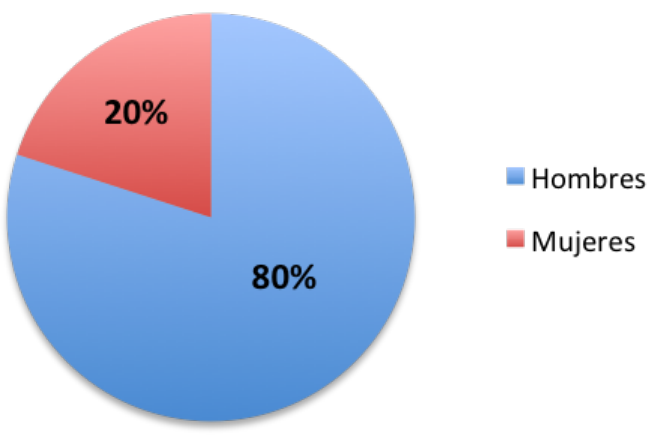

Fuente: Elaboración propia.

Incluso, con el aumento sustancial de producciones que se viene dando desde el año 2001 a la fecha, la presencia de mujeres directoras continúa siendo baja. Las nueve películas costarricenses dirigidas por mujeres fueron estrenadas durante este periodo, por lo que, si solo tomamos en cuenta las 35 obras entre el año 2001 al 2016, el porcentaje sube a 25\%, que es la misma proporción para el periodo 2008-2012 en el que se enfoca el presente estudio (ver Figura 5) ${ }^{3}$.

Figura 5. Dirección de largometrajes de ficción costarricenses, por sexo, 2008-2012

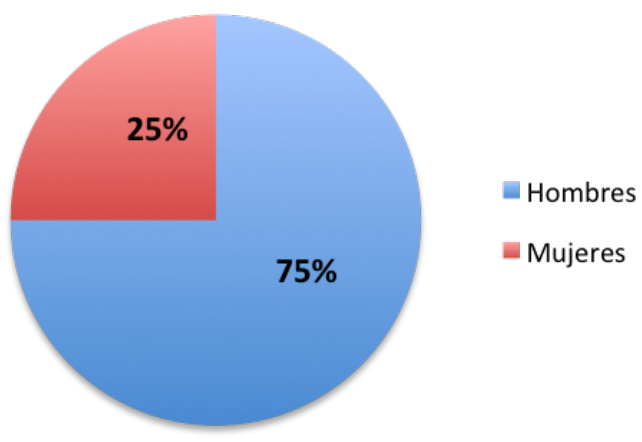

Fuente: Elaboración propia.

3 La muestra de estudio es de 15 largometrajes, pero dado que una de las obras ("El ultimo comandante") fue dirigida por una dupla de hombre y mujer, se contabiliza para ambos géneros. Así pues, las cifras y porcentajes presentados se calculan sobre un total de 16. 
El género de los personajes protagónicos es otro aspecto interesante de analizar, en cuanto se trata de la figura central alrededor de la cual se construye el proyecto dramático de la narrativa. Cuando se toman los cuatro largometrajes dirigidos por mujeres (ver Figura 6) y se indaga el género de sus protagonistas; vemos que dos tienen a mujeres como personajes principales ("El camino", "Agua fría de mar"), y los otros dos muestran un protagonismo compartido de hombres y mujeres ("Del amor y otros demonios", "El último comandante").

\section{Figura 6. Distribución por sexo de personajes protagónicos en películas dirigidas por mujeres, 2008-2012}

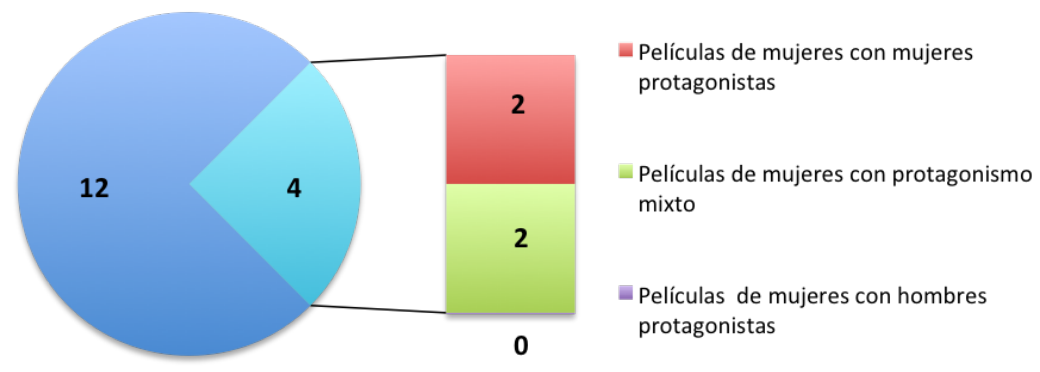

Fuente: Elaboración propia.

Si analizamos el mismo aspecto en las obras dirigidas por hombres (ver Figura 7), descubrimos que la mayor parte de esos relatos muestran un protagonismo compartido, mientras que tres de ellos colocan exclusivamente a hombres en la función protagónica ("El Psicópata", "El Sanatorio", "El Fin”).

Resulta llamativo que en ambos casos, la presencia del género opuesto como protagonista exclusivo es nula. Es decir, no aparecen hombres como únicos protagonistas en las películas dirigidas por mujeres, ni mujeres como únicas protagonistas en las películas dirigidas por hombres. Mientras esto puede ser entendible en el primer caso, en el que las mujeres disponen de menos espacios para contar sus propias historias, la situación apunta a una tarea pendiente (o un nicho por aprovechar) para los autores masculinos, cuyas obras son las que dominan la oferta fílmica. 
Figura 7. Distribución por sexo de personajes protagónicos en películas dirigidas por hombres, 2008-2012

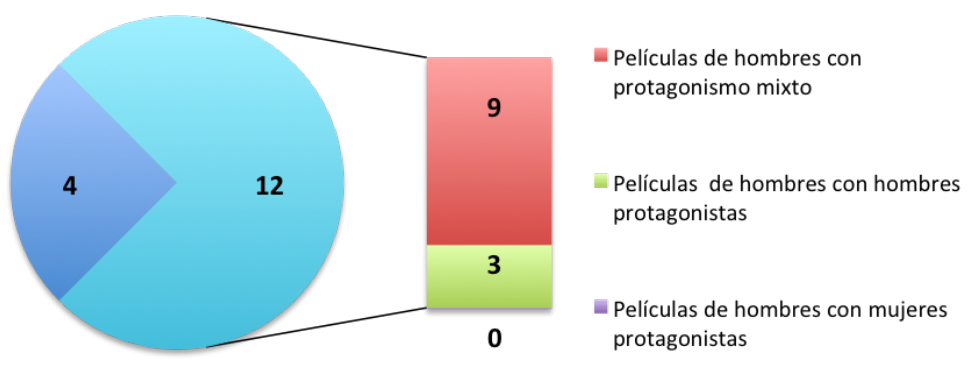

Fuente: Elaboración propia.

En cuanto a la frecuencia de las funciones actanciales identificadas para los personajes femeninos de los largometrajes de la muestra (ver Figura 8), podemos apreciar que la representación dominante de la mujer según el modelo de Greimas es el de ayudante: en el 93\% de los casos, las mujeres dentro de las narrativas apoyan y colaboran el accionar de un sujeto (usualmente masculino) en pos de su objeto de deseo. El segundo rol más común (87\%) es el de objeto de deseo en sí, donde se presenta a la mujer como meta a alcanzar, específicamente como interés romántico o sexual de los personajes masculinos.

Figura 8. Frecuencia de funciones actanciales en largometrajes de ficción costarricenses, 2008-2012

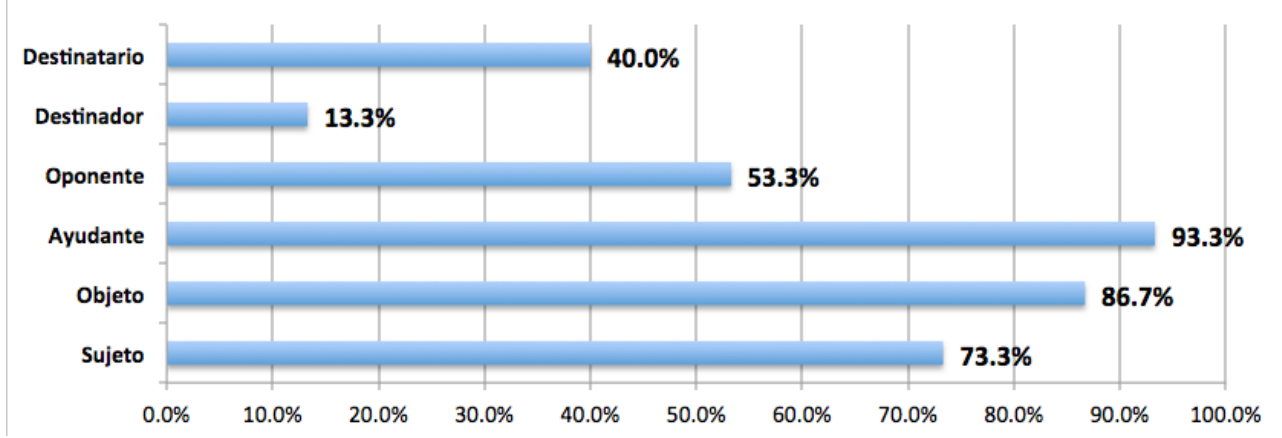

Fuente: Elaboración propia. 


\begin{tabular}{|c|c|c|c|c|c|c|}
\hline & Sujeto & Objeto & Ayudante & Oponente & Destinador & Destinatario \\
\hline El camino & $x$ & $x$ & $x$ & & & \\
\hline El Psicópata & & $x$ & $x$ & & & $x$ \\
\hline La Región Perdida & $x$ & $x$ & $x$ & & & $x$ \\
\hline Gestación & $x$ & $x$ & $\mathbf{x}$ & $x$ & $x$ & $x$ \\
\hline Tercer Mundo & $x$ & $x$ & $x$ & & & \\
\hline $\begin{array}{l}\text { Del amor y otros } \\
\text { demonios }\end{array}$ & & $x$ & $x$ & $x$ & & \\
\hline Donde duerme el horror & $x$ & $x$ & $x$ & $x$ & & \\
\hline A ojos cerrados & $x$ & & $x$ & $x$ & & \\
\hline El último comandante & $x$ & & $x$ & $x$ & $x$ & \\
\hline Agua fría de mar & $x$ & $x$ & $x$ & $x$ & & \\
\hline El Sanatorio & & $x$ & $x$ & & & \\
\hline El Regreso & $x$ & $x$ & $x$ & $x$ & & $x$ \\
\hline El Compromiso & $x$ & $x$ & $x$ & $x$ & & \\
\hline El Fin & & $x$ & & & & $x$ \\
\hline Tres Marías & $x$ & $x$ & $x$ & & & $x$ \\
\hline
\end{tabular}

Fuente: Elaboración propia.

La función de la mujer como sujeto aparece en un tercer lugar, en un $73 \%$ de los ejemplos analizados. Aquí debemos recordar que para esta tabulación no solo se toma en cuenta la presencia de un personaje central femenino (de lo que dan cuenta las Figuras 6 y 7), sino que se amplía el campo de aplicación de la herramienta para identificar si los personajes femeninos, en general, exhiben las características de deseo y proactividad que definen la función del sujeto actancial. En otras palabras, esta cifra rescata la naturaleza autónoma y activa de las mujeres dentro del mundo narrativo, sean estas las protagonistas de la historia o no.

En contraste, las funciones menos comunes en los casos de estudio son las del eje de transmisión: el actante como destinatario (40\%) y como destinador (13\%). Esto significa que la figura de la mujer dentro de estos relatos es escasamente representada como la beneficiaria de la acción del sujeto, y menos aún como la instigadora o motivadora de dicha actividad. En el rango medio (53\%) encontramos a la mujer como oponente, la función actancial dedicada a impedir el avance y la culminación del objetivo del sujeto.

Mención aparte merece la frecuencia de las funciones del modelo actancial dentro de los ejemplos específicos de análisis. Aquí se confirma que la mayoría de los casos incluyen a la mujer en funciones de sujeto, objeto y/o 
ayudante; pero, también, podemos observar como algunos textos incluyen mayor o menor cantidad de estos roles dentro de su formulación narrativa (ver tabla en Figura 8). Los dos ejemplos más visibles son "Gestación", que presenta a la mujer en todas las seis funciones actanciales; mientras que "El Fin" lo hace solamente en dos (como objeto y como destinatario). Aunque es claro que la utilización de todas las funciones actanciales no constituye una garantía, se podría argumentar que es un primer paso hacia la construcción de representaciones dramáticas más realistas y multidimensionales de género.

Finalmente, tenemos los datos que arroja la aplicación del Test de Bechdel a la muestra de estudio (ver Figura 9). Aquí se hace una distinción no solo entre los textos que aprueban los criterios del test y los que no, sino que también se hace la salvedad de aquellos que lo aprueban "con reservas". Por esto me refiero a narrativas que cumplen con los requisitos de (1) contar con al menos dos personajes femeninos con nombres, y (2) que muestren a estos personajes sosteniendo una conversación; pero, donde el cumplimiento del último criterio -(3) que dicha conversación no sea sobre un hombre-, no sea del todo clara o satisfactoria. Esto a raíz de que existen múltiples diálogos a través de la muestra en donde si bien hay instantes en donde las personajes se refieren a diversos asuntos, esos momentos forman parte de un intercambio mayor en donde sí se refieren a un hombre, ya sea directa o indirectamente.

Figura 9. Test de Bechdel vs largometrajes de ficción costarricenses, 2008-2012

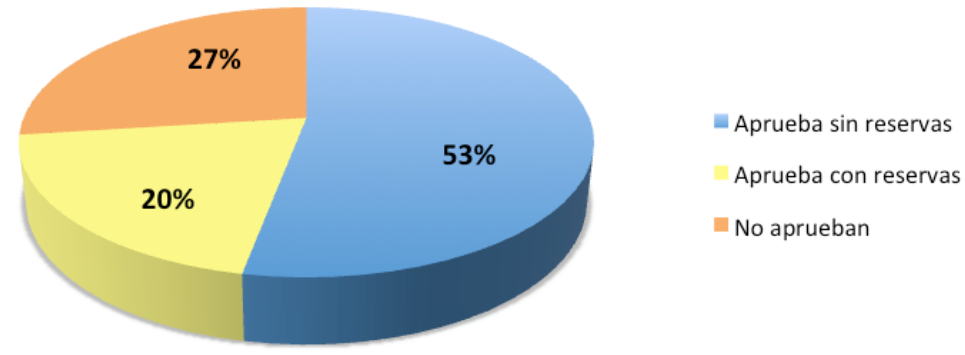

Fuente: Elaboración propia. 


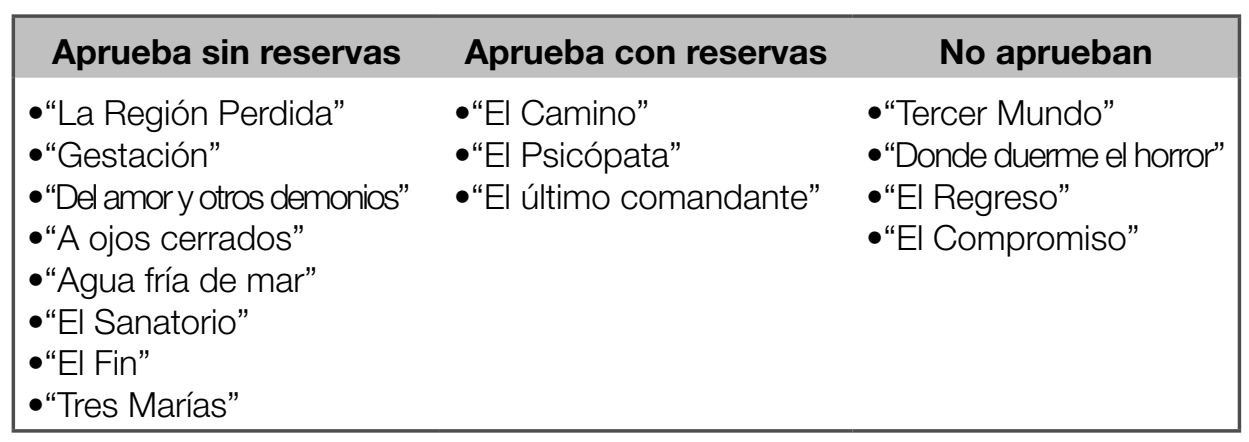

Fuente: Elaboración propia.

En cualquier caso, podemos observar que una mayoría de los textos (53\%) aprueban sin reservas el Test de Bechdel, 20\% lo aprueba con la reserva mencionada anteriormente, y un $27 \%$ no lo aprueban. No obstante, es necesario reiterar el carácter más informal y anecdótico de estos resultados, los cuales pueden no ser consistentes con los de la aplicación del modelo actancial a la hora de determinar si un film ofrece una representación dramática equilibrada entre los géneros. Por ejemplo, nótese que obras como "El Psicópata", "El Sanatorio" y "El Fin" aprueban el Test de Bechdel, aun cuando se trata de los tres largometrajes dirigidos por hombres con protagonistas exclusivamente masculinos y sin una sola mujer en función actancial de sujeto; mientras que otras narrativas que sí cuentan con personajes femeninos protagónicos y activos ("Tercer Mundo", "El Regreso", "El Compromiso") no lo aprueban.

Así pues, el Test de Bechdel puede ser una herramienta útil si se utiliza en conjunto con otro método de análisis más profundo (en este caso, el modelo actancial), con el fin de contrastar si las estructuras subyacentes de representación se reflejan a nivel de la interacción verbal entre sus personajes.

\section{Reflexión final}

Varias décadas después del surgimiento de la teoría fílmica feminista y sus textos fundantes, las preocupaciones centrales sobre la relación entre la mujer y el cine parecen seguir siendo esencialmente las mismas. La falta de acceso a los medios de producción, la construcción distorsionada de la feminidad, y el predominio de una mirada masculina que articula la representación de la mujer como subordinada al hombre, son algunas de las cuestiones que encendieron esta tradición crítica y que hoy vemos reflejadas en nuestro propio cine de ficción. 
El surgimiento de un grupo de mujeres directoras y sus obras en los primeros años de este nuevo siglo ha venido a romper el monopolio de la autoría masculina de largometrajes, y a aportar con ello una perspectiva y un acento inéditos en la generación de historias cinematográficas en nuestro país. El cambio sin duda ha iniciado; no obstante, el presente estudio sugiere que los patrones retóricos patriarcales aún continúan sólidos en su lugar, con una representación dominante de la mujer como facilitadora de proyectos de acción que no son propios, y como objeto de deseo del otro.

La frecuencia en que la mujer aparece como sujeto de acción en este análisis es considerable; pero como ya se ha explicado anteriormente, debemos tener en cuenta que muchas de esas instancias son paralelas o secundarias al proyecto principal del relato, donde el protagonismo de la mujer sigue siendo opacado por el del hombre, incluso en casos de protagonismo conjunto ("Tercer Mundo", "Donde duerme el horror", "El último comandante”, entre otras).

El auge en la producción de largometrajes de los últimos años constituye un crecimiento de nuestro cine no solo en número, sino también en la calidad profesional y artística de las obras. Vivimos un momento histórico propicio para que, tanto desde la práctica como desde la academia, reflexionemos sobre lo que se realiza actualmente e identifiquemos carencias, necesidades, nuevos nichos y oportunidades que contribuyan al desarrollo del campo.

Estudios como este pretenden ser un modesto aporte en esa línea, reiterando la importancia de contar no solo con una mayor cantidad de voces femeninas en la oferta fílmica nacional, sino también con una revolución a nivel narrativo, que nos aleje de añejos patrones y nos acerque a propuestas que -independientemente del género de su autor- reivindiquen la autonomía, el dinamismo, la riqueza y la diversidad de roles de la mujer en la sociedad. Esto, como se ha sugerido anteriormente, puede empezar con simples modificaciones a nivel actancial, como la utilización de personajes femeninos en una función de sujeto-protagonista más inequívoca dentro del texto narrativo; y/o una representación de los personajes femeninos mejor distribuida a través de las distintas funciones actanciales, en lugar de limitada a unas pocas.

Considero que estos esfuerzos de monitoreo discursivo deben ser aplicados no solo de forma continua a través del tiempo y la acumulación de nuevas obras, sino también complementados con estudios de recepción que den cuenta de las maneras en que estas representaciones están siendo interpretadas y apropiadas por la audiencia. Se trata, pues, de reconocer y vigilar el enorme poder de un medio como el cine, con el fin de garantizar la difusión de las múltiples facetas de la realidad social, evitar su empleo como herramienta de discriminación o violencia simbólica, y promover a través de este la equidad y justicia de género. 


\section{Referencias}

Bilge, Sirma \& Scheibelhofer, Paul. (2012). Unravelling the new politics of racialised sexualities: Introduction. Journal of Intercultural Studies, 33(3), pp. 255-259.

Bordwell, David. (1985). Narration in the Fiction Film. London: Routledge.

Butler, Judith. (1990). Gender Trouble. Feminism and the subversion of identity. New York: Routledge. Recuperado de http://www.lauragonzalez.com/TC/ BUTLER_gender_trouble.pdf

Cortés, María Lourdes. (2002). El espejo imposible: un siglo de cine en Costa Rica. San José, Costa Rica: Ediciones Farben.

Cortés, María Lourdes. (2011). El nuevo cine costarricense. Revista Comunicación, Año 32, 20(2), 4-17.

Cortés, María Lourdes. (2016). Fabulaciones del cine costarricense. (pendiente de publicación)

Hébert, Louis. (2006). The Actantial Model. Signo: Theoretical Semiotics on the Web. Recuperado de http://www.signosemio.com/greimas/actantial-model.asp.

Larsen, Peter. (2002). Mediated Fiction. En Klaus Bruhn Jensen (Ed.), A Handbook of Media and Communication Research: Qualitative and Quantitative Methodologies (pp. 117-138). London: Routledge.

Mulvey, Laura. (1975). Visual Pleasure and Narrative Cinema. Screen, 16(3), 6-18. Recuperado de http://imlportfolio.usc.edu/ctcs505/mulveyVisualPleasureNarrativeCinema.pdf

Sarkeesian, Anita. (2009). The Bechdel Test for Women in Movies. Feminist Frequency: Conversations with Pop Culture. Recuperado de http://feministfrequency.com/2009/12/07/the-bechdel-test-for-women-in-movies/

Smelik, Anneke. (2016). Feminist Film Theory. The Wiley-Blackwell Encyclopedia of Gender and Sexuality Studies. Recuperado de http://www.let. uu.nl/womens_studies/anneke/filmtheory.html

Stam, Robert. (2000). Film Theory: An Introduction. Malden, Mass: Blackwell Publishers.

Stam, Robert, Burgoyne, Robert \& Flitterman-Lewis, Sandy. (1992). New Vocabularies in Film Semiotics: Structuralism, Post-structuralism and beyond. London: Routledge. 